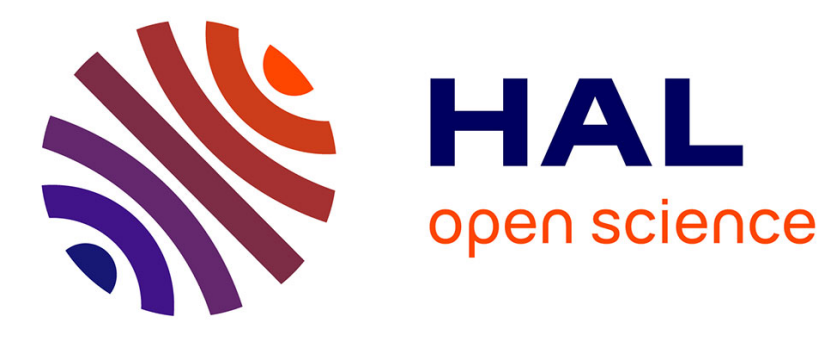

\title{
Absolute acidity of clay edge sites from ab-initio simulations
}

Sami Tazi, Benjamin Rotenberg, Mathieu Salanne, Michiel Sprik, Marialore Sulpizi

\section{- To cite this version:}

Sami Tazi, Benjamin Rotenberg, Mathieu Salanne, Michiel Sprik, Marialore Sulpizi. Absolute acidity of clay edge sites from ab-initio simulations. Geochimica et Cosmochimica Acta, 2012, 94, pp.1 - 11. 10.1016/j.gca.2012.07.010 . hal-01917859

\section{HAL Id: hal-01917859 https://hal.sorbonne-universite.fr/hal-01917859}

Submitted on 9 Nov 2018

HAL is a multi-disciplinary open access archive for the deposit and dissemination of scientific research documents, whether they are published or not. The documents may come from teaching and research institutions in France or abroad, or from public or private research centers.
L'archive ouverte pluridisciplinaire HAL, est destinée au dépôt et à la diffusion de documents scientifiques de niveau recherche, publiés ou non, émanant des établissements d'enseignement et de recherche français ou étrangers, des laboratoires publics ou privés. 


\title{
Absolute acidity of clay edge sites from ab-initio simulations
}

Sami Tazi, Benjamin Rotenberg*, and Mathieu Salanne UPMC Univ Paris 06, CNRS, ESPCI, UMR 7195, PECSA, F-75005 Paris, France

\author{
Michiel Sprik \\ Department of Chemistry, University of Cambridge, Cambridge, United Kingdom \\ Marialore Sulpizi \\ Johannes Gutenberg University, Staudingerweg 7, 55099, Mainz, Germany
}

* corresponding author: benjamin.rotenberg@upmc.fr 


\begin{abstract}
We provide a miscroscopic understanding of the solvation structure and reactivity of the edges of neutral clays. In particular we address the tendency to deprotonation of the different reactive groups on the (010) face of pyrophyllite. Such information cannot be inferred directly from titration experiments, which do not discriminate between different sites and whose interpretation resorts to macroscopic models. The determination of the corresponding $\mathrm{p} K_{a}$ then usually relies on bond valence models, sometimes improved by incorporating some structural information from abinitio simulations. Here we use Density Functional Theory based molecular dynamics simulations, combined with thermodynamic integration, to compute the free energy of the reactions of water with the different surface groups, leading to a deprotonated site and an aqueous hydronium ion. Our approach consistently describes the clay and water sides of the interface and includes naturally electronic polarization effects. It also allows to investigate the structure and solvation of all sites separately. We find that the most acidic group is $\mathrm{SiOH}$, due to its ability to establish strong hydrogen bonds with adsorbed water, as it also happens on the quartz and amorphous silica surfaces. The acidity constant of $\mathrm{AlOH}_{2}$ is only $1 \mathrm{p} K_{a}$ unit larger. Finally, the $\mathrm{p} K_{a}$ of $\mathrm{AlOH}$ is outside the possible range in water and this site should not deprotonate in aqueous solution. We show that the solvation of surface sites and hence their acidity is strongly affected by the proximity of other sites, in particular for $\mathrm{AlOH}$ and $\mathrm{AlOH}_{2}$ which share the same $\mathrm{Al}$. We discuss the implications of our findings on the applicability of bond valence models to predict the acidity of edge sites of clays.
\end{abstract}




\section{INTRODUCTION}

The acido-basic properties of clay minerals play a key role in their surface chemistry. The increased acidity of water confined in smectite clay interlayers [Bergaya et al. 2006], for example, contributes to its catalytic properties. The protonation state of the edges of clay layers has an impact on both the stability of colloidal clay suspensions [Tombácz and Szekeres 2004] and on the sorption of ions [Baeyens and Bradbury 1997, Bradbury and Baeyens 1997]. This is particularly important since the retention of contaminants by argillaceous rocks is pivotal in the current concepts for the geological disposal of long-lived high-level nuclear waste in several countries such as Switzerland, France and Belgium [ANDRA 2005, Bradbury and Baeyens 2003]. Clays are lamellar aluminosilicate minerals. While the negative charge of their basal surface builds up because of isomorphic substitutions in the mineral lattice, that of edge sites (which arise from the finiteness of the sheets) is due to the deprotonation or protonation of surface groups. The protonation state is then controlled by the acidity of the various groups and the $\mathrm{pH}$ of the solution.

Several difficulties arise when trying to address the question of acidity from an experimental point of view. The most problematic one for the assignment of individual $\mathrm{p} K_{a}$ 's to the different surface groups is that macroscopic measurements such as titration experiments cannot distinguish between them. Moreover, Bourg et al. have shown recently that the analysis of such experiments must be performed with great care, in particular to correctly take into account the surface charge at the onset of titration [Bourg et al. 2007]. In the wait for the use of site-specific techniques (e.g. spectroscopic ones), the most promising approach has been to interpret experiments within the framework of a conceptual model, relying on assumptions (e.g. on the reactions to consider or how to decouple electrostatic from chemical contributions) and associated parameters (equilibrium constants for the various reactions) [Baeyens and Bradbury 1997, Bradbury and Baeyens 1997]. The predictions of the model are then compared to the limited and global experimental data. In the best case, a favourable comparison could still occur by a compensation of errors between the different assumptions and parameters underlying the prediction [Bourg et al. 2007]. In order to limit this risk, Tournassat et al. have proposed to constrain a large number of parameters from structure-based models [Tournassat et al. 2004]. More precisely, the density of each site can be predicted from the structure of the mineral layer and the corresponding acidity constants 
estimated using semi-empirical bond-valence based models such as MUSIC [Bickmore et al. 2006, 2004, Brown 2009, Hiemstra et al. 1996, Tournassat et al. 2004]. Nevertheless, there has been to date no direct way to probe the charge density on the edge and to measure the deprotonation free energies of the different sites. Another indirect strategy to determine the overall protonation state of clay edges has been proposed by Zhao et al. who found using Atomic Force Microscopy that the force between a silica tip and a surface consisting of muscovite edges turned from repulsive at $\mathrm{pH} \sim 10$ to attractive at $\mathrm{pH} \sim 6$, from which they concluded that these edge surfaces had a point of zero charge of pH 7-8. [Zhao et al. 2008]

In this respect atomistic simulations have emerged as a powerful tool to address the microscopic properties of clays. While force-field based, classical molecular simulations have for example provided insights on bulk clays (including interlayer water and ion dynamics [Ferrage et al. 2011, Marry and Turq 2003, Marry et al. 2002, Rinnert et al. 2005], swelling [Boek et al. 1995, Tambach et al. 2004] and ion exchange [Rotenberg et al. 2009, Teppen and Miller 2006]), or on ion sorption [Greathouse and Cygan 2005] and water at basal surfaces [Marry et al. 2008, Rotenberg et al. 2011, Wang et al. 2006, 2009], their application to clay edges have been so far limited [Rotenberg et al. 2007, 2010]. One of the main reasons is that the description of interfaces often requires to address polarization effects and, in the case of clay edges, reactivity. Electronic structure calculations provide a direct way to include such effects describing both the solid and the liquid in a consistent way. In the last years Density functional Theory (DFT)-based molecular dynamics simulations have provided a first principle understanding of bulk clays such as the properties of interlayer ions [Boek and Sprik 2003, Suter et al. 2008] and their vibrational properties [Larentzos et al. 2007], or of water at basal surfaces [Bridgeman et al. 1996, Tunega et al. 2002, 2004]. More recently, the acidity of interlayer water [Churakov and Kosakowski 2010, Liu et al. 2011] and the structure and reactivity of clay edges [Bickmore et al. 2003, Kremleva et al. 2011, Liu et al. 2008, 2012] have also been investigated. In particular, Churakov has studied water confined between edges of pyrophyllite. He evidenced transient proton exchange between surface groups mediated by surface water molecules [Churakov 2007] and proposed a first attempt to provide an acidity scale of the surface groups from their deprotonation energy in vacuum [Churakov 2006]. In this context, it has also been suggested that ab-initio simulations could provide refinements of the bond-valence based models of acidity by introducing the relaxation of bond lengths [Bickmore et al. 2003] (whose importance was already suggested 
by White and Zelazny [White and Zelazny 1988]) or the solvation structure (coordination and bond lengths) [Machesky et al. 2008] determined from DFT simulations.

One possible approach to compute the acidity of surface sites is to compute the potential of mean force along a suitable reaction coordinate, as was done by Leung et al. for silica [Leung et al. 2009] and goethite [Leung and Criscenti 2012]. DFT-based ab-initio simulations can also be combined with thermodynamic integration to determine the free energy of proton transfer from a given site to a water molecule, which provides a direct measure of the acidity of this site. This strategy has been successfully employed to calculate the $\mathrm{p} K_{a}$ of simple aqueous compounds [Cheng et al. 2009, Costanzo et al. 2011, Mangold et al. 2011, Sulpizi and Sprik 2010, 2008] as well as the surface acidity and point of zero charge of simple oxides in contact with water, namely titania [Cheng and Sprik 2010], quartz [Sulpizi et al. 2012] and alumina [Gaigeot et al. 2012]. In the present work, we apply this strategy to provide the first direct calculation of the $\mathrm{p} K_{a}$ of the different groups which are present on the (010) face of pyrophyllite. We first introduce the simulated system and computational method used to determine the deprotonation free energy. We then compute the $\mathrm{p} K_{a}$ of the three edge sites present on this surface, namely $\mathrm{SiOH}, \mathrm{AlOH}$ and $\mathrm{AlOH}_{2}$. We further analyze the changes in structure and solvation of each site upon deprotonation and relate them to the reorganization free energies. Finally, we compare our results to previous estimates for the same edges and for similar sites on other mineral surfaces, and discuss the predictions of the MUSIC model.

\section{METHODS}

\section{A. Acidity constant calculations}

The acidity constants of the different reactive groups present on the clay edge are computed using the reversible proton insertion/deletion method [Cheng et al. 2009, Costanzo et al. 2011, Mangold et al. 2011, Sulpizi and Sprik 2010, 2008]. pK $K_{a}$ 's are estimated from the reaction free energies for the transfer of a proton from the surface to a water molecule in the bulk part of the sample. For example, if we consider the silanol site as a reference, this reads:

$$
-\mathrm{SiOH}+\mathrm{H}_{2} \mathrm{O}_{a q} \rightarrow-\mathrm{SiO}^{-}+\mathrm{H}_{3} \mathrm{O}_{a q}^{+}
$$


The free energy of this transfer process is computed using thermodynamic integration. The charge of the acidic proton of a surface $\mathrm{OH}$ group is gradually switched off transforming it into a neutral dummy ("ghost") hydrogen atom which is tethered to the oxygen but otherwise does not interact with the rest of the system. Simultaneously a similar dummy hydrogen attached to a water molecule is charged up, creating a hydronium $\mathrm{H}_{3} \mathrm{O}^{+}$in the Eigen form. Following the approach discussed in detail in Ref. [Costanzo et al. 2011], the reaction free energy for the deprotonation process is calculated according to the following integral [King and Warshel 1990]:

$$
\Delta A=\int_{0}^{1} \mathrm{~d} \eta\langle\Delta E\rangle_{\eta}
$$

where $\Delta E$ is the vertical energy gap, defined as the potential energy difference between products $\mathrm{P}\left(-\mathrm{SiO}^{-}+\mathrm{H}_{3} \mathrm{O}_{a q}^{+}\right.$in Eq. 1) and reactants $\mathrm{R}\left(-\mathrm{SiOH}+\mathrm{H}_{2} \mathrm{O}_{a q}\right)$ for instantaneous configurations of a molecular dynamics trajectory. The subscript $\eta$ indicates that the averages are evaluated over the restrained mapping Hamiltonian $\mathcal{H}_{\eta}=(1-\eta) \mathcal{H}_{\mathrm{R}}+\eta \mathcal{H}_{\mathrm{P}}$, where $\eta$ is a coupling parameter which is gradually increased from 0 ( $-\mathrm{SiOH}+\mathrm{H}_{2} \mathrm{O}_{a q}$ ) to $1\left(-\mathrm{SiO}^{-}+\mathrm{H}_{3} \mathrm{O}_{a q}^{+}\right)$. This Hamiltonian also contains a harmonic restraining potential $V_{\text {restr }}$, independent of $\eta$, keeping the dummy atoms close to the equilibrium position of the $\mathrm{H}^{+}$nucleus in the protonated site and hydronium, as explained in the next section. The Simpson rule (three point approximation) is used to evaluate the integral in Eq. 2:

$$
\Delta A_{\mathrm{TP}}=\frac{1}{6}\left(\langle\Delta E\rangle_{0}+\langle\Delta E\rangle_{1}\right)+\frac{2}{3}\langle\Delta E\rangle_{0.5}
$$

This requires the generation of three trajectories corresponding to values of $\eta=0,0.5,1$. Simulation length for each value of $\eta$ are reported in Table I. The three point formula is often a good compromise between computational cost and accuracy of the free energy change [Hummer and Szabo 1996, Sulpizi and Sprik 2008]. However, if the curvature of $\langle\Delta E\rangle_{\eta}$ is large, more integration points may be required. According to the derivation in Ref. [Costanzo et al. 2011] the expression for the $\mathrm{p} K_{a}$, in the low temperature limit to the quantum vibrational partition function of the acid proton, reads:

$$
2.30 k_{\mathrm{B}} T \mathrm{p} K_{a}=k_{\mathrm{B}} T \ln \left[c^{\mathrm{o}} \Lambda_{\mathrm{H}^{+}}^{3}\right]+\int_{0}^{1} \mathrm{~d} \eta\langle\Delta E\rangle_{\eta}
$$

where $c^{\mathrm{o}}=1 \mathrm{~mol} \mathrm{dm}^{-3}$ is the unit molar concentration, and $\Lambda_{\mathrm{H}^{+}}$is the thermal wavelength of the proton. The logarithm of the product $c^{\mathrm{o}} \Lambda_{\mathrm{H}^{+}}^{3}$ accounts for the liberation entropy of the proton and is responsible for a correction of $-3.2 \mathrm{p} K_{a}$ units to the thermodynamic integral. 
Finite system size effects are of course a point of concern in these calculations [Costanzo et al. 2011]. In the present case, since the system is overall neutral, we do not expect issues related to the presence of net charges (and compensating background) as also discussed in Ref. [Churakov 2006]. The dimensions of the system considered here (see below) are similar to previous studies of other mineral surfaces for which finite site effects could be estimated as being smaller than the uncertainty on the final $\mathrm{p} K_{a}$ value.

When considering the intrinsic acidity of different sites on the same surface, one must ensure that less acidic sites will not be reprotonated by proton transfer from more acidic ones. Similarly, for sites whose $\mathrm{p} K_{a}$ is outside the water domain (0-14), one must prevent proton transfer from water to the deprotonated sites, to really sample the products of the surface deprotonation reaction. This can be achieved in simulations by introducting additional restraining potentials on $\mathrm{O}-\mathrm{H}$ bonds that are not considered for the deprotonation. Since these constraints are present in both the initial and final states, they do not contribute to the free energy difference (as for the tethering of the dummy hydrogens) in Eq. 2. Essentially, the $\mathrm{p} K_{a}$ value reflects the absolute acidity of a given site, conditional to the fact that the rest of the surface remains unchanged, i.e. as if this site was isolated on the surface. Once these values have been determined, one can draw a predominance diagram to predict the actual state of the surface as a function of $\mathrm{pH}$.

\section{B. System and simulation details}

We simulate a finite neutral pyrophyllite particle in contact with a slab of bulk liquid water along its (010) face. The simulation box contains 312 atoms, namely 12 aluminum, 24 silicium, 80 oxygen (of which 8 form $\mathrm{SiO}$ edge sites, $8 \mathrm{AlO}$ edge sites and $8 \mathrm{OH}$ groups), 28 hydrogen atoms (of which 8 form $\mathrm{SiOH}$ edge sites $4 \mathrm{AlOH}$ edge sites, $8 \mathrm{AlOH}_{2}$ edge sites and the 8 last the $\mathrm{OH}$ groups), 56 water molecules. The unit cell is orthorhombic with dimensions $\mathrm{L}_{x}=10.36 \AA, \mathrm{L}_{y}=9.35 \AA$ and $\mathrm{L}_{z}=31.0 \AA$. Periodic boundary conditions allow to simulate an infinite stack along $y$ of sheets which are infinite along the $x$ direction and finite along the $z$ one (See Fig.1).

The initial configuration for the DFT-based molecular dynamics is prepared using a classical molecular dynamics simulation in which the clay particle is fixed and the water equilibrated in the NVT ensemble at $300 \mathrm{~K}$. The SPC/E model [Berendsen et al. 1987] for 
water and the CLAYFF force field [Cygan et al. 2004] for clay are used and the equations of motion for the rigid water molecules are integrated using the SHAKE algorithm [Ryckaert et al. 1977]. DFT-based simulations are performed with the PBE functional [Perdew et al. 1996], analytic Goedecker-Teter-Hutter [Goedecker et al. 1996, Hartwigsen et al. 1998] pseudopotentials and DZVP-MOLOPT [VandeVondele and Hutter 2007] basis sets with a cut-off of 280 Ry. Only the $\Gamma$ point of the Brillouin zone was considered and simulations were performed at $350 \mathrm{~K}$, which is the usual condition to simulate water under ambient conditions with the PBE functional. Both the force field and DFT based molecular dynamics simulations were performed with the CP2K package [CP2K developers group, http://cp2k.org ]. For the DFT calculations, the latter uses an algorithm based on the hybrid Gaussian and plane wave method [Lippert et al. 1997]. In order to analyze the electronic charge redistribution upon deprotonation, we have computed the density-derived atomic partial charges (DDPAC) according to Ref. [Blöchl 1995]. A charge calculation is performed for configurations along the molecular dynamics trajectory, and average values are reported.

The harmonic restraining potential $V_{\text {restr }}$ used for the thermodynamic integration to maintain the dummy proton close to the equilibrium position reads:

$$
V_{\text {restr }}=\sum_{i=1}^{n_{d}} \frac{1}{2} k_{d, i}\left(d_{i}-d_{0, i}\right)^{2}+\sum_{j=1}^{n_{\alpha}} \frac{1}{2} k_{\alpha, j}\left(\alpha_{j}-\alpha_{0, j}\right)^{2}
$$

where the first sum corresponds to restraining the distance $d$ from the nearby oxygen atom to the equilibrium value $d_{0}$ in the protonated form and the second to the angles involving the dummy proton. The equilibrium values are determined from a prior simulation without restraints, while the restraining parameters have been chosen according to the prescriptions of Ref. [Sulpizi and Sprik 2008]. Details on the number of terms and on the corresponding parameters are reported for each site in Table II. The choice of a particular water molecule to form the hydronium is not relevant provided that this molecule is beyond the second solvation shell of the acidic surface proton under investigation. 


\section{RESULTS AND DISCUSSION}

\section{A. Structure of the interface}

The structure of the (010) face of pyrophyllite interface with a water film has already been investigated in detail by Churakov [Churakov 2007], and we provide here the main features to serve as a reference for the discussion of the deprotonated sites. Moreover, we have used different simulation conditions, in particular a larger clay fragment and a wider water region, and this preliminary analysis allows to investigate the possible differences. The water density is equal to the bulk density except for the adsorbed layers, and its structure differs slightly from that of liquid water because of confinement. Nevertheless, it remains liquid-like. As can be seen in Fig. 1, the clay plane is tilted with respect to the directions of the simulation box. This tilt allows the bottom and top surfaces of the clay sheet to be placed relative to each other (taking into account the periodic boundary conditions) in accordance with the geometry of the bulk clay unit cell. This orientation of the clay is not frozen and fluctuates during the simulations, as a result of the relatively small size of the clay particle considered here. However the solid-liquid interface always remains perpendicular to the $z$ direction and the two surfaces are equivalent.

Three different deprotonable groups are present on the (010) edge, namely $\mathrm{SiOH}, \mathrm{AlOH}_{2}$, and $\mathrm{AlOH}$ as can bee seen on the insert of Fig. 1. Their solvation can be analyzed in terms of the coordination numbers of the $\mathrm{O}$ and $\mathrm{H}$ surface atoms by water (and other surface atoms) and the distance to the corresponding neighbours. The results are summarized in Table III and the hydrogen bond patterns are depicted in Fig. 2. In particular, silanol groups $(\mathrm{SiOH})$ donate strong $\mathrm{H}$-bonds and accept weaker ones, while $\mathrm{AlOH}_{2}$ groups only donate $\mathrm{H}$-bonds and $\mathrm{AlOH}$ groups only accept them. Moreover, some $\mathrm{H}$-bonds are formed between surface groups, e.g. between $\mathrm{AlOH}_{2}$ and $\mathrm{SiOH}$. Meanwhile, $\mathrm{AlOH}$ groups do not exchange H-bonds with other surface groups, accept $~ 1.8 \mathrm{H}$-bonds from water and donate none. Finally, $\mathrm{AlOH}_{2}$ groups do not accept any H-bonds, donate $\sim 0.65$ to water and $\sim 0.25$ to surface groups. Within small quantitative variations, all these results confirm the findings of Churakov [Churakov 2007]. Overall, the coordination number of the oxygen atom on these groups is appproximately 3 for $\mathrm{AlOH}_{2}(2 \mathrm{H}$ and $1 \mathrm{Al}), 4$ for $\mathrm{AlOH}(3 \mathrm{H}$ and $1 \mathrm{Al})$ and 3 for $\mathrm{SiOH}(2 \mathrm{H}$ and $1 \mathrm{Si})$. 


\section{B. Acidity of surface groups}

We now turn to the calculation of the $\mathrm{p} K_{a}$ of the edge sites using the thermodynamic integration method explained above, during which the acid proton in each $\mathrm{OH}$ group on the clay edge is gradually removed and transferred into the aqueous solution. The convergence of the three vertical energy gaps corresponding to $\eta=0,0.5$ and 1 is illustrated for the $\mathrm{SiOH}$ site in Fig. 3. The $\mathrm{p} K_{a}$ of the different surface groups are given in Table IV. We find that the most acidic site is $\mathrm{SiOH}$, with a $\mathrm{p} K_{a}$ of $6.8 \pm 0.4$, closely followed by $\mathrm{AlOH}_{2}$ $\left(\mathrm{p} K_{a}=7.6 \pm 1.3\right)$. Finally the $\mathrm{AlOH}$ group is the less keen to loose a proton, with a $\mathrm{p} K_{a}$ of $22.1 \pm 1.0$. In order to understand the relative acidity of these sites, it is instructive to analyze the contributions of the vertical energy gaps $\Delta \mathrm{E}_{A H}$ and the reorganization free energies $\lambda$, to the overall reaction free energies $\Delta A$, which are summarized in Table IV. The vertical energy gap measures how difficult it is to deprotonate the site without changing the structure (bond lengths, solvation) around it, while $\lambda=\Delta \mathrm{E}_{A H}-\Delta A$ quantifies the stabilizing effect of structural relaxation (including solvation) [Hummer and Szabo 1996]. For each reaction, all these quantities include an identical contribution of the protonation of a water molecule to form a hydronium, so that differences between them really reflect what happens on each site.

The deprotonation of $\mathrm{SiOH}$ is stabilized by the arrival of two water molecules donating H-bonds, increasing the coordination number of the oxygen atom from approximately 3 (1 Si, 1 bonded $\mathrm{H}$ and 1 accepted H-bond) to 4 (1 Si and 3 accepted H-bond), without change in the distance of the first neighbours $R_{O \cdots H}$ (see Table III). This allows an efficient stabilization of the deprotonated site (large $\lambda$ ) which contributes favorably to the reaction. Other possible contributions to the stabilization include the charge redistribution and the relaxation of the Si-O bond length. As can be seen in Table V, there is no significant change in the partial charge of the Si and O upon deprotonation, while Table VI indicates that the shortening (from $1.64 \pm 0.03$ to $1.60 \pm 0.03 \AA$ ) of the Si-O bond is very limited.

The deprotonation of $\mathrm{AlOH}$ involves a larger vertical gap and a smaller reorganization free energy, compared to $\mathrm{SiOH}$. This means that this site is both intrinsically more difficult to deprotonate and less stabilized by subsequent reorganization of the surface. When $\mathrm{AlOH}$ deprotonates, the coordination number of the oxygen hardly changes, however the nature of the neighbours changes, from $1 \mathrm{Al}, 1$ bonded $\mathrm{H}$ and 2 accepted H-bonds to $1 \mathrm{Al}$ and 3 
accepted H-bonds. One also observes a shortening of the distance to the donating water molecules $\left(R_{O \cdots H}\right.$ decreases from 1.65 to $1.60 \AA$ ) and of the Al-O bond (from 1.86 to $1.73 \AA$ ) as well as a moderate charge redistribution (with an increase in the partial charge of $\mathrm{O}$ from -0.9 e to -1.1 e). The most spectacular change, however, is the departure of the $\mathrm{OH}_{2}$ group adjacent to $\mathrm{AlOH}$ as a water molecule, with a resulting decrease in the coordination of $\mathrm{Al}$ from 6 to 5, as can be seen in Fig. 4. Such a phenomenon was recently investigated on the neutral surface by Liu et al., who found a free energy cost of $3 \mathrm{kcal} / \mathrm{mol}\left(\approx 5 k_{\mathrm{B}} T\right)$ for the departure of the water molecule (hence a relatively low probability for this event on the neutral surface) [Liu et al. 2012]. It is this departure which opens the way to the third donating water molecule to stabilize the deprotonated site. Nevertheless, all these structural reorganizations are not sufficient to counterbalance the effect of an otherwise larger vertical gap, leading to a larger $\mathrm{p} K_{a}$.

Finally, for $\mathrm{AlOH}_{2}$ the two terms play in opposite directions. While the vertical gap $\Delta \mathrm{E}_{A H}$ is smaller than for $\mathrm{SiOH}$, possibly thanks to the presence of a remaining $\mathrm{H}$ to stabilize the charge on the deprotonated site, the reorganization is less efficient (smaller $\lambda$ ). In that case, the coordination number of oxygen decreases slightly from 3 (1 Al and 2 bonded $\mathrm{H})$ to approximately 2.75 ( $1 \mathrm{Al}, 1$ bonded $\mathrm{H}$ and 0.75 accepted $\mathrm{H}$-bond). The change is limited due to steric constraints, as no additional molecule can approach this site. The final situation corresponds to a transfer of the proton from $\mathrm{AlOH}_{2}$ to a water molecule that was receiving a H-bond from this site. This molecule then transferred one of its initial $\mathrm{H}$ atoms to another molecule, according to the Grotthus mechanism, leading to a hydronium ion further away from the surface and a deprotonated site stabilized by accepting a H-bond from the surface water whose dipole is now oriented toward the surface. There is no change in the partial charges and a decrease in the Al-O bond length (from 2.05 to $1.85 \AA$ ). The resulting deprotonated group is in fact identical (in terms of geometry and partial charges) to the other hydroxyl present on the same $\mathrm{Al}$ before deprotonation. Nevertheless, there is an asymmetry between these two sites from the point of view of solvation: Whereas $\mathrm{AlOH}$ on the neutral surface is coordinated by two surface water molecules, there is only one around the deprotonated $\mathrm{AlOH}_{2}$ site. This arises from a crowding effect, as no more than three molecules can approach the ligands of the Al: This steric constraint implies that only one molecule can stabilize the deprotonated site, since two others already donate H-bonds to the neighbouring $\mathrm{OH}$ group. Overall, the balance between these two effects is hard to predict 
and the reaction free energy is only $0.05 \mathrm{eV}$ larger from that for $\mathrm{SiOH}$, leading to a moderate $\mathrm{p} K_{a}$ difference.

In order to evaluate the integral (2), the computationally more efficient end point approximation is not sufficiently accurate because of the non-linear response of the solvent and resort to the three-point formula (3) is necessary. As already commented in our recent work [Cheng and Sprik 2010, Cheng et al. 2009, Costanzo et al. 2011, Gaigeot et al. 2012, Mangold et al. 2011, Sulpizi and Sprik 2010, 2008, Sulpizi et al. 2012] the deprotonation event involves a highly non-linear response of the solvent reorganization. An easy to monitor indicator of deviations from linearity is the dependence of the variance of the energy gap fluctuations on protonation state. Comparing the standard deviation of the gap distribution in the protonated and deprotonated trajectory, denoted by $\sigma_{A H}$ and $\sigma_{A-}$ respectively in Table IV, we notice that $\sigma_{A-}$ is larger than $\sigma_{A H}$. An additional observation is that if $\sigma_{A H}$ is the same for all the systems investigated, $\sigma_{A-}$, however, exhibits some variations and we therefore can not count on cancellation of corrections to linear response when comparing the different systems.

\section{Comparison with previous estimates}

As mentioned previously, direct comparison with experimental data is not possible, since such measurements for individual sites on a given clay edge are to date not available. However we can compare our data with previous estimates obtained with empirical methods based on bond-valence models, as will be discussed below, and previous DFT-based estimates of the deprotonation enthalpies $\Delta \mathrm{H}_{\text {dep }}^{\text {vacuum }}$ for the same sites in vacuum by Churakov [Churakov 2006]. In the latter study, only one value, for $\mathrm{AlOH}_{2}$, was directly calculated from the relaxed deprotonated surface while the others were estimated from an empirical relation involving the partial charge of the oxygen atom (also determined from DFT calculations). These estimates concluded that $\Delta \mathrm{H}_{\text {dep }}^{\text {vacuum }}$ was most negative for $\mathrm{AlOH}_{2}$, followed by $\mathrm{SiOH}$ and $\mathrm{AlOH}$. We find that the vertical energy gaps on the solvated surface are consistent with this order, i.e. that it is easier to deprotonate $\mathrm{AlOH}_{2}$, followed by $\mathrm{SiOH}$ and $\mathrm{AlOH}$, for configurations of the interfacial water corresponding to the protonated sites. However, the relaxation of the surface water molecules also contributes to the reaction enthalpy (and so does the formation of a solvated hydronium ion, which is common to the three deproto- 
nation reactions). Overall, we measure reaction enthalpies $\Delta \mathrm{H}_{\text {dep }}^{\text {solv }}=\left\langle\mathrm{E}_{A^{-}}\right\rangle-\left\langle\mathrm{E}_{A H}\right\rangle$, with the energies corresponding to averages of the deprotonated (resp. protonated) state along the deprotonated (resp. protonated) trajectory, for the reaction between weak or very weak acids with water, which are smaller than the corresponding statistical error of $\approx 0.05 \mathrm{eV}$. It thus seems that the agreement between the deprotonation enthalpy in vacuum and the deprotonation free energy is somewhat fortuitous. In a later study of water confined between pyrophyllite edges, Churakov reported transient proton exchange between $\mathrm{SiOH}$ or $\mathrm{AlOH}_{2}$ on the one hand and $\mathrm{AlOH}$ on the other hand, via surface water molecules [Churakov 2007]. While we did not observe such rare events during the course of our simulations, possibly due to subtle changes in the organization of water molecule in a twice larger water slab in our case, this suggests that the acidity of these sites is comparable and indeed larger than that of $\mathrm{AlOH}$.

Most previous acidity estimates for edge sites of clays follow from bond-valence based empirical models such as MUSIC [Hiemstra et al. 1996]. One of the major appeals of such models is their ability to obtain estimates of $\mathrm{p} K_{a}$ for oxides or hydroxides in a very simple way. The main assumptions underlying the MUSIC model are (i) that the $\mathrm{p} K_{a}$ of an acid can be estimated from the structure of the corresponding base (ii) an empirical linear relation between the $\mathrm{p} K_{a}$ and the valence of this oxygen and its neighbours, fitted on experimental $\mathrm{p} K_{a}$ 's of acids in homogenous solution, which implicitly includes information on the protonated state (iii) estimates for the coordination number and contribution of each neighbour to the valence of the oxygen. The application of this method from solutes to oxide surfaces, in particular clay edges, has already been considered. Tournassat et al. have applied this strategy using the original method, which makes use of a priori values for the coordination numbers and valence contribution of bonded $\mathrm{H}$ atoms, received $\mathrm{H}$-bonds and metals [Tournassat et al. 2004]. The latter depends on the metal-oxygen distance and Bickmore et al. have demonstrated that surface relaxation after deprotonation (in vacuum) may contribute to the change in valence, hence in $\mathrm{p} K_{a}$ [Bickmore et al. 2003, 2004]. Moreover, it was subsequently shown that the MUSIC model could be improved by incorporating structural information (bond length and coordination numbers) from DFT calculations [Bickmore et al. 2006], eventually leading to the revised MUSIC model [Machesky et al. 2008].

In Table VII we compare different $\mathrm{p} K_{a}$ estimates from the MUSIC model using different values for the coordination numbers and valence units for the neighbouring $\mathrm{H}$ (attached to 
the $\mathrm{O}$ or received from H-bonds) and metal (see Appendix for details of the MUSIC model). In the first version, we report the results of Tournassat et al. who used the a priori recommendations of the original MUSIC model for coordination numbers and valences [Tournassat et al. 2004]. In model II, coordination numbers from the DFT simulations are used. Finally, in the revised version (model III), both coordination numbers and valences are determined from the DFT simulations [Machesky et al. 2008]. The estimates of the original model are in remarkable agreement with that of the present work: The value for $\mathrm{AlOH}$ is almost the same as ours, out of the water domain; that for $\mathrm{SiOH}$ and $\mathrm{AlOH}_{2}$ are on the alkaline side, with a $K_{a}$ for the latter approximately one unit larger than for the former, although both are larger than ours. Interestingly, for the modelling of titration curves, which was the main purpose of Tournassat et al., a smaller value than the one predicted by MUSIC was used for $\mathrm{SiOH}$ (8.2 instead of 9.1) to obtain a better agreement with the experiments. This suggests that our prediction of a more acidic $\mathrm{SiOH}$ group might reflect more accurately the experimental situation.

As can be seen in Table VII, the actual coordination numbers are not very different from the a priori estimates, so that the prediction of model II are still reasonable (although shifted in the wrong direction for $\mathrm{SiOH}$ and $\mathrm{AlOH}_{2}$ ). Introducting the valences from DFT, computed as explained in Ref. [Machesky et al. 2008] only worsens all predictions, yielding in particular very acidic $\mathrm{SiOH}$ and $\mathrm{AlOH}$ sites. From this comparison we conclude that the original method provides the closest agreement with the prediction of thermodynamic integration, but this agreement is fortuitous, since including information on the correct structure and valence, which are the physical ingredients underlying this model, does not improve the result. This suggest that including such information on the deprotonated state only is not sufficient to capture the free energy of reaction, which accounts for the changes between the initial and final states. As discussed above, the reaction free energies for all three sites include a large contribution of the reorganization free energies and the structure of the deprotonated state might be very different from that of the protonated one, especially in the $\mathrm{AlOH}$ case for which deprotonation is followed by the departure of the neighbouring $\mathrm{OH}_{2}$ group (this prediction for the intrinsic acidity of this site assumes that no proton transfer between surface groups occurs, while this would happen in practice because the other groups are more acidic). This particular case confirms that such empirical models, while very useful thanks to their simplicity, should be used with caution when applied to 
surfaces. The proximity of the various sites results in correlations between their solvation shell, especially when several sites share the same metallic ion ( $\mathrm{Al}$ in the present case).

\section{Comparison with other surfaces}

It is interesting to compare our findings with previous calculations on simple oxides. For example, for the (0001) surface of quartz some of us have found 2 types of silanols, "outof-plane" and "in-plane", with different acidity constants, namely 5.6 and 8.5 [Sulpizi et al. 2012]. Here the silanols are preferentially out-of-plane. As can bee seen in Table III and Fig. 2, they donate a H-bond to water $\left(n_{H \cdots O_{w}}=0.92\right)$ and accept H-bonds mainly from water H (0.80 H-bonds) and occasionally from nearby surface groups (0.26 H-bond from $\mathrm{AlOH}_{2}$ ). Such strong H-bonds donated by silanols to water have also been observed on the (0001) quartz surface [Gaigeot et al. 2012, Sulpizi et al. 2012]. The higher $\mathrm{p} K_{a}$ of the silanol groups on the (010) edges of pyrophyllite with respect to the out-of-plane silanols on the quartz (0001) surface could be due to the nearby surface groups, and in particular the less strong H-bond accepted from $\mathrm{AlOH}_{2}$.

We can also compare the results for the aluminol acidity with previous calculations on the (0001) surface of alumina. The main difference in this case is in the coordination of the oxygen with the metal. Indeed in the present case, the $\mathrm{OH}$ group in $\mathrm{AlOH}$ is singly coordinated by aluminum, while on the (0001) surface of alumina the OH group of the $\mathrm{Al}_{2} \mathrm{OH}$ aluminol is doubly coordinated by $\mathrm{Al}$. This difference also has a quite strong impact on the solvation structure of the the respective $\mathrm{OH}$ groups. In the case of $\mathrm{Al}_{2} \mathrm{OH}$ aluminols, the $\mathrm{OH}$ donates a not so strong $\mathrm{H}$-bond to water and accepts a quite strong one from another water molecule, while on the (010) edge of pyrophyllite $\mathrm{AlOH}$ groups do not donate any $\mathrm{H}$-bond to water and only accept one. Overall, the stronger interaction of this surface hydroxyl group with water in alumina correlates with a smaller $\mathrm{p} K_{a}$ of 16.6 [Gaigeot et al. 2012], compared to 22.1 in the present case.

\section{CONCLUSION}

We have determined the acidity of the $\mathrm{SiOH}, \mathrm{AlOH}$ and $\mathrm{AlOH}_{2}$ groups present on the (010) edge of pyrophyllite, using DFT-based molecular dynamics simulations combined with 
thermodynamic integration. We have found that the most acidic group is SiOH, closely followed by $\mathrm{AlOH}_{2}$ and that $\mathrm{AlOH}$ should not deprotonate in water. We have shown that the deprotonation of each site is followed by moderate changes in bond lengths and charge distributions, but sometimes more consequent changes in solvation. The solvation of surface sites and hence their acidity is strongly influenced by the proximity of other sites, in particular for $\mathrm{AlOH}$ and $\mathrm{AlOH}_{2}$ which share the same Al. Introducing the DFT-derived bond lengths and valence units in the MUSIC worsens its predictions, which are surprisingly (but fortuituously, since it relies on incorrect assumptions in this case) in reasonable agreement with our estimates. The $\mathrm{p} K_{a}$ values suggest that around $\mathrm{pH}=7$ the sorption of ions on this face should occur only on the $\mathrm{SiO}^{-}$and deprotonated $\mathrm{AlOH}_{2}$ which, considering the presence of the other hydroxyl group, can be seen as $\mathrm{Al}(\mathrm{OH})_{2}^{-}$, sites.

Several natural extensions of this work include the study of additional sites, e.g. $\mathrm{SiOH}_{2}^{+}$, $\mathrm{AlOH}_{2}^{+}$or protonated bridging $\mathrm{SiOAl}$ sites, and different faces of pyrophyllite, in particular the (110) one, and of substituted clays such as montmorillonite. Indeed, the presence of substitutions in the tetrahedral $\left(\mathrm{Si}^{4+} \rightarrow \mathrm{Al}^{3+}\right)$ and octahedral $\left(\mathrm{Al}^{3+} \rightarrow \mathrm{Mg}^{2+}\right)$ layers influences the affinity for water [Liu et al. 2012] and the acidity of surface groups. Another direct application could be the use of the $\mathrm{p} K_{a}$ values to predict titration curves using e.g. the analytical approach of Bourg et al. [Bourg et al. 2007] or the simulation strategy of Delhorme et al. [Delhorme et al. 2010]. This would provide an indirect way to confront our results to experimental data. A direct test of our predictions could eventually come in the near future thanks to the rapid development of surface sensitive experimental probing the solid-liquid interface, such as Sum Frequency Generation (SFG) spectroscopy [Eisenthal 1996, Shen 1989].

The present study opens the way to the accurate simulation of the sorption of ions onto edge sites of clay minerals. Not only does it allow to predict the protonation state of the surface, which is a key factor. It also provides insights for the development of accurate force fields for classical molecular dynamics simulations. For example, the fact that after deprotonation of $\mathrm{AlOH}_{2}$ both hydroxyl groups are identical suggest that polarizable ion models, which have been successfully developped for the description of molten and crystalline oxides and hydroxides [Salanne et al. 2012] might be well suited to also describe edge sites of aluminosilicate minerals. Resort to classical molecular dynamics will then allow to sample configurations over sufficiently long time scales to investigate the sorption/desorption 
processes.

\section{Acknowledgments}

The authors thank Rodolphe Vuilleumier for useful discussions and acknowledge financial support from the Agence Nationale de la Recherche under grant ANR-09-SYSC-012. This work was performed using HPC resources from GENCI-CINES/IDRIS (Grants c2010086491, c2011086491 and c2012086491). This work was carried out under the HPC-EUROPA2 project (project number: 228398) with the support of the European Commission Capacities Area - Research Infrastructures Initiative. S. T. is grateful to Alexey Cheptsov for technical assistance during his visit.

\section{Appendix: Acidity estimates with the MUSIC model}

The MUSIC model allows to estimate the $\mathrm{p} K_{a}$ of a site from the coordination number of the oxygen by hydrogen atoms ( $m \mathrm{H}$ on the site, $n \mathrm{H}$ from other molecules), their valencies ( $s_{H}$ for the former, $1-s_{H}$ for the latter) and the metal valencies $s_{M e_{i}}$ as:

$$
\mathrm{p} K_{a}=A\left[V+m s_{H}+n\left(1-s_{H}\right)+\sum_{i} s_{M e_{i}}\right]
$$

In this expression, $A=19.8$ is a constant whose value is determined from regressions of experimental data for aqueous acids, $V=-2$ is the oxygen valency, while the metal valencies are determined from the corresponding metal-oxygen distances $r_{M e O_{i}} \operatorname{as} \exp \left(\left(r_{0 i}-r_{M e O_{i}}\right) / b\right)$ with $b=0.37 \AA$ and $r_{0 i}$ reference bond lengths calculated from bulk crystal structures. In this work, we compare our results from thermodynamic integration with three variants of the MUSIC model where the coordination numbers and valencies are determined according to different prescriptions (see text). The coordination numbers and valencies reported in Tab. VII from DFT calculations are computed using a cut-off of $r_{c}=2.375 \AA$ as [Machesky et al. 2008]:

$$
s=n\left(1.55-1.06 R_{\text {avg }}+0.186 R_{\text {avg }}^{2}\right)
$$

with $n$ the coordination number and

$$
R_{a v g}=\frac{\int_{0}^{r_{c}} r g_{O H}(r) r^{2} \mathrm{~d} r}{\int_{0}^{r_{c}} g_{O H}(r) r^{2} \mathrm{~d} r}
$$


where $g_{O H}$ is the radial distribution function.

ANDRA. Évaluation de la faisabilité du stockage géologique en formation argileuse. Dossier 2005 Argile : Synthèse, Châtenay-Malabry, France, 2005.

B. Baeyens and M. H. Bradbury. A mechanistic description of Ni and Zn sorption on Namontmorillonite part I: Titration and sorption measurements. J. Contam. Hydrol., 27:199-222, 1997.

H.J.C. Berendsen, J.R. Grigera, and T.P. Straatsma. The missing term in effective pair potentials. J. Phys. Chem., 91(24):6269-6271, 1987.

F. Bergaya, B. G. K. Theng, and D. Ladaly. Handbook of clay science. Elsevier, Amsterdam, 2006.

B. Bickmore, K. Rosso, C. Tadanier, E. Bylaska, and D. Doud. Bond-valence methods for pKa prediction. ii. bond-valence, electrostatic, molecular geometry, and solvation effects. Geochim. Cosmochim. Acta, 70:4057-4071, 2006.

B. R. Bickmore, K. M. Rosso, K. L. Nagy, R. T. Cygan, and C. J. Tadanier. Ab initio determination of edge surface structures for dioctahedral 2:1 phyllosilicates: implications for acid-base for reactivity. Clays Clay Miner., 51:359-371, 2003.

B. R. Bickmore, C. J. Tadanier, K. M. Rosso, W. D. Monn, and D. L. Eggett. Bond-valence methods for pKa prediction: critical reanalysis and a new approach1. Geochim. Cosmochim. Acta, 68:2025-2042, 2004.

P. E. Blöchl. Electrostatic decoupling of periodic images of plane-wave expanded densities and derived atomic point charges. J. Chem. Phys., 103:7422-7428, 1995.

E. S. Boek and M. Sprik. Ab initio molecular dynamics study of the hydration of a sodium smectite clay. J. Phys. Chem. B, 107:3251-3256, 2003.

E.S. Boek, P.V. Coveney, and N.T. Skipper. Monte Carlo molecular modelling studies of hydrated Li-, Na- and K-smectites: Understanding the role of potassium as a clay swelling inhibitor. J. Am. Chem. Soc., 117(50):12608-12617, 1995.

I. C. Bourg, G. Sposito, and A. C. M. Bourg. Modeling the acid-base surface chemistry of montmorillonite. J. Colloid Interf. Sci., 312:297-310, 2007.

M. Bradbury and B. Baeyens. Near Field Sorption Data Bases for Compacted MX-80 Bentonite for Performance Assessment of a High-Level Radioactive Waste Repository in Opalinus Clay Host 
Rock. Paul Scherrer Institut, Switzerland, 2003.

Michael H. Bradbury and Bart Baeyens. A mechanistic description of Ni and Zn sorption on Na-montmorillonite part II: Modelling. J. Contam. Hydrol., 27:223-248, 1997.

C.H. Bridgeman, A.D. Buckingham, N.T. Skipper, and M.C. Payne. Ab-initio total energy study of uncharged 2:1 clays and their interaction with water. Mol. Phys., 89:879-888, 1996.

I. D. Brown. Recent developments in the methods and applications of the bond valence model. Chem. Rev., 109:6858-6919, 2009.

J. Cheng and M. Sprik. Acidity of the aqueous rutile TiO2(110) surface from density functional theory based molecular dynamics. J. Chem. Theory Comput., 6:880, 2010.

J. Cheng, M. Sulpizi, and M. Sprik. Redox potentials and pKa for benzoquinone from density functional theory based molecular dynamics. J. Chem. Phys., 131:154504, 2009.

S. V. Churakov. Ab initio study of sorption on pyrophyllite: structure and acidity of the edge sites. J. Phys. Chem. B, 110:4135-4146, 2006.

S. V. Churakov. Structure and dynamics of the water films confined between edges of pyrophyllite: a first principle study. Geochim. Cosmochim. Acta, 71:1130-1144, 2007.

S. V. Churakov and G. Kosakowski. An ab initio molecular dynamics study of hydronium complexation in na-montmorillonite. Philosophical Magazine, 90:2459-2474, 2010.

F. Costanzo, M. Sulpizi, Valle R.G., and M. Sprik. The oxidation of tyrosine and tryptophan studied by a molecular dynamics normal hydrogen electrode. J. Chem. Phys., 134:244508, 2011. CP2K developers group, http://cp2k.org . URL http://cp2k.berlios.de.

R. T. Cygan, J.-J. Liang, and A. G. Kalinichev. Molecular models of hydroxide, oxyhydroxide, and clay phases and the development of a general force field. J. Phys. Chem. B, 108:1255-1266, 2004 .

M. Delhorme, C. Labbez, C. Caillet, and F. Thomas. Acid-base properties of 2:1 clays. i. modeling the role of electrostatics. Langmuir, 26(12):9240-9249, 2010. doi: 10.1021/la100069g.

K. B. Eisenthal. Liquid interfaces probed by second-harmonic and sum-frequency spectroscopy. Chem. Rev., 96:1343, 1996.

E. Ferrage, B. A. Sakharov, L. J. Michot, A. Delville, A. Bauer, B. Lanson, S. Grangeon, G. Frapper, M. Jiménez-Ruiz, and G. J. Cuello. Hydration properties and interlayer organization of water and ions in synthetic na-smectite with tetrahedral layer charge. part 2. toward a precise coupling between molecular simulations and diffraction data. J. Phys. Chem. C, 115(5):1867-1881, 2011. 
M.-P. Gaigeot, M. Sprik, and M. Sulpizi. Oxide/water interfaces: how the surface chemistry modifies interfacial water properties. J. Phys. Cond. Matt., 24:124106, 2012.

S. Goedecker, M. Teter, and J. Hutter. Separable dual-space gaussian pseudopotentials. Phys. Rev. B, , 54:1703, 1996.

J. A. Greathouse and R. T. Cygan. Molecular dynamics simulation of uranyl(vi) adsorption equilibria onto an external montmorillonite surface. Phys. Chem. Chem. Phys., 7:3580-3586, 2005.

C. Hartwigsen, S. Goedecker, and J. Hutter. Relativistic separable dual-space gaussian pseudopotentials from h to rn. Phys. Rev. B, 58:3641, 1998.

T. Hiemstra, P. Vanema, and W. H. Van Riemsdijk. Intrinsic proton affinity of reactive surface groups of metal (hydr)oxides: The bond valence principle. J. Coll. Interf. Sci., 184(2):680-692, 1996.

G. Hummer and A. Szabo. Calculation of free energy differences from computer simulations of initial and final states. J. Chem. Phys., 105:2004, 1996.

G. King and A. Warshel. Investigation of the free energy functions for electron transfer reactions. J. Chem. Phys., 93:8682, 1990.

A. Kremleva, S. Krüger, and N. Rösch. Uranyl adsorption at (010) edge surfaces of kaolinite: A density functional study. Geochim. Cosmochim. Acta, 75:706-718, 2011.

J. P. Larentzos, J. A. Greathouse, and R. T. Cygan. An ab initio and classical molecular dynamics investigation of the structural and vibrational properties of talc and pyrophyllite. J. Phys. Chem. C, 111(34):12752-12759, 2007.

K. Leung and L.J. Criscenti. Predicting the acidity constant of a goethite hydroxyl group from first principles. J. Phys.: Condens. Matter, 24:124105, 2012.

K. Leung, I.M.B. Nielsen, and L.J. Criscenti. Elucidating the bimodal acid-base behavior of the water-silica interface from first principles. J. Am. Chem. Soc., 131(51):18358-18365, 2009.

G. Lippert, J. Hutter, and Parrinello M. A hybrid gaussian and plane wave density functional scheme. Mol. Phys., 92:477, 1997.

X. Liu, X. Lu, R. Wang, H. Zhou, and S. Xu. Surface complexes of acetate on edge surfaces of 2:1 type phyllosilicate: Insights from density functional theory calculation. Geochim. Cosmochim. Acta, 72:5896-5907, 2008.

X. Liu, X. Lu, R. Wang, E. J. Meijer, and H. Zhou. Acidities of confined water in interlayer space of clay minerals. Geochim. Cosmochim. Acta, 75:4978-4986, 2011. 
X. Liu, X. Lu, E. J. Meijer, R. Wang, and H. Zhou. Atomic-scale structures of interfaces between phyllosilicate edges and water. Geochim. Cosmochim. Acta, 81:56-68, 2012.

M. L. Machesky, M. Predota, D. J. Wesolowski, L. Vlcek, P. T. Cummings, J. Rosenqvist, M. K. Ridley, J. D. Kubicki, A. V. Bandura, N. Kumar, and J. O. Sofo. Surface protonation at the rutile (110) interface: Explicit incorporation of solvation structure within the refined music model framework. Langmuir, 24(21):12331-12339, 2008. doi: 10.1021/la801356m.

M. Mangold, L. Rolland, F. Costanzo, M. Sprik, M. Sulpizi, and J. Blumberger. Absolute pK(a) values and solvation structure of amino acids from density functional based molecular dynamics simulation. J. Chem. Theory Comput., 7:1951, 2011.

V. Marry and P. Turq. Microscopic simulations of interlayer structure and dynamics in bihydrated heteroionic montmorillonites. J. Phys. Chem. B, 107:1832-1839, 2003.

V. Marry, P. Turq, T. Cartailler, and D. Levesque. Microscopic simulation for structure and dynamics of water and counterions in a monohydrated montmorillonite. J. Chem. Phys., 117: 3454-3463, 2002.

V. Marry, B. Rotenberg, and P. Turq. Structure and dynamics of water at a clay surface from molecular dynamics simulation. Phys. Chem. Chem. Phys., 10:4802-4813, 2008.

J. P. Perdew, K. Burke, and M. Ernzerhof. Generalized gradient approximation made simple. Phys.

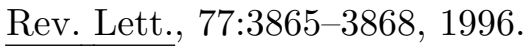

E. Rinnert, C. Carteret, B. Humbert, G. Fragneto-Cusani, J. D. F. Ramsay, A. Delville, J.-L. Robert, I. Bihannic, M. Pelletier, and L. J. Michot. Hydration of a synthetic clay with tetrahedral charges: A multidisciplinary experimental and numerical study. J. Phys. Chem. B, 109(49):23745$23759,2005$.

B. Rotenberg, V. Marry, R. Vuilleumier, N. Malikova, C. Simon, and P. Turq. Water and ions in clays : Unraveling the interlayer/micropore exchange using molecular dynamics. Geochim. et Cosmochim. Acta, 71:5089-5101, 2007.

B. Rotenberg, J.P. Morel, V. Marry, P. Turq, and N. Morel-Desrosiers. On the driving force of cation exchange in clays : Insights from combined microcalorimetry experiments and molecular simulation. Geochim. et Cosmochim. Acta, 73:4034-4044, 2009.

B. Rotenberg, V. Marry, N. Malikova, and P. Turq. Molecular simulation of aqueous solutions at clay surfaces. J. Phys.: Condens. Matter, 22:284114, 2010.

B. Rotenberg, A. J. Patel, and D. Chandler. Molecular explanation for why talc surfaces can be 
both hydrophilic and hydrophobic. J. Am. Chem. Soc., 133:20521-20527, 2011.

J.-P. Ryckaert, G. Ciccotti, and H. J. C. Berendsen. Numerical integration of the cartesian equations of motion of a system with constraints: molecular dynamics of $n$-alkanes. J. Comput. Phys., 23(3):327-341, 1977.

M. Salanne, B. Rotenberg, S. Jahn, R. Vuilleumier, C. Simon, and P. A. Madden. Including many-body effects in models for ionic liquids. Theor. Chem. Acc., 131:1143, 2012.

Y. R. Shen. Surface properties probed by 2nd harmonic and sum-frequency generation. Nature, $337: 519,1989$

M. Sulpizi and M. Sprik. Acidity constants from dft-based molecular dynamics simulations. J. Phys.: Condens. Matter, 22(28):284116, 2010.

M. Sulpizi and M. Sprik. Acidity constants from vertical energy gaps: density functional theory based molecular dynamics implementation. Phys. Chem. Chem. Phys., 10:5238, 2008.

M. Sulpizi, M.P. Gaigeot, and M. Sprik. The silica-water interface: how the silanols determine the surface acidity and modulate the water properties. J. Chem. Theory Comput., 8(3), 2012.

J. L. Suter, E. S. Boek, and M. Sprik. Adsorption of a sodium ion on a smectite clay from constrained ab initio molecular dynamics simulations. J. Phys. Chem. C, 112:18832-18839, 2008. T. J. Tambach, E. J. M. Hensen, and B. Smit. Molecular simulations of swelling clay minerals. J. Phys. Chem. B, 108(23):7586-7596, 2004.

B. J. Teppen and D. M. Miller. Hydration energy determines isovalent cation exchange selectivity by clay minerals. Soil Sci. Soc. Am. J., 70(1):31-40, 2006.

E. Tombácz and M. Szekeres. Colloidal behavior of aqueous montmorillonite suspensions: the specific role of $\mathrm{pH}$ in the presence of indifferent electrolytes. Appl. Clay Sci., 27:75-94, 2004.

C. Tournassat, E. Ferrage, C. Poinsignon, and L. Charlet. The titration of clay minerals ii. structure-based model and implications for clay reactivity. J. Colloid Interface Sci., 273:234-246, 2004.

D. Tunega, G. Haberhauer, M. H. Gerzabek, and H. Lischka. Theoretical study of adsorption sites on the (001) surfaces of 1:1 clay minerals. Langmuir, 18:139-147, 2002.

D. Tunega, M. H. Gerzabek, and H. Lischka. Ab initio molecular dynamics study of a monomolecular water layer on octahedral and tetrahedral kaolinite surfaces. J. Phys. Chem. B, 108:5930-5936, 2004.

J. VandeVondele and J. Hutter. Gaussian basis sets for accurate calculations on molecular systems 
in gas and condensed phases. J. Chem. Phys., 127:114105, 2007.

J. Wang, A. G. Kalinichev, and R. Kirkpatrick. Effects of substrate structure and composition on the structure, dynamics, and energetics of water at mineral surfaces: A molecular dynamics modeling study. Geochim. et Cosmochim. Acta, 70:562-582, 2006.

J. Wang, Andrey G. Kalinichev, and R. J. Kirkpatrick. Asymmetric hydrogen bonding and orientational ordering of water at hydrophobic and hydrophilic surfaces: A comparison of water/vapor, water/talc, and water/mica interfaces. J. Phys. Chem. C, 113:11077-11085, 2009.

G. N. White and L. W. Zelazny. Analysis and implications of the edge structure of dioctaedral phyllosilicates. Clays Clay Miner., 36:14-146, 1988.

H. Zhao, S. Bhattacharjee, R. Chow, D. Wallace, J. H. Masliyah, and Z. Xu. Probing surface charge potentials of clay basal planes and edges by direct force measurements. Langmuir, 24:12899-12910, 2008 . 


\begin{tabular}{|l|c|c|c|}
\hline \multirow{2}{*}{ Site } & \multicolumn{3}{|c|}{ Simulation time $(\mathrm{ps})$} \\
\cline { 2 - 4 } & $\eta=0.0$ & $\eta=0.5$ & $\eta=1.0$ \\
\hline $\mathrm{SiOH}$ & 17.0 & 22.1 & 18.1 \\
$\mathrm{AlOH}$ & 8.6 & 8.7 & 11.4 \\
$\mathrm{AlOH}_{2}$ & 19.1 & 17.6 & 17.7 \\
\hline
\end{tabular}

TABLE I: Simulated time (in ps) for each value of the coupling parameter $\eta$ and each site.

\begin{tabular}{|l|ccc|ccc|}
\hline Site & $\mathrm{n}_{d}$ & $\mathrm{~d}_{0}$ & $\mathrm{k}_{d}$ & $\mathrm{n}_{\alpha}$ & $\alpha_{0}$ & $\mathrm{k}_{\alpha}$ \\
\hline $\mathrm{AlOH}$ & 1 & 0.98 & 0.2 & 1 & 116 & 0.2 \\
$\mathrm{SiOH}$ & 1 & 1.01 & 0.2 & 1 & 118 & 0.2 \\
$\mathrm{AlOH}_{2}$ & 1 & 1.03 & 0.2 & 2 & $109 / 121$ & 0.2 \\
$\mathrm{H}_{3} \mathrm{O}^{+}$ & 3 & 1.00 & 0.2 & 2 & 111 & 0.2 \\
\hline
\end{tabular}

TABLE II: List of the parameters employed in the harmonic potential Eq. (5) restraining the dummy acid protons in the deprotonated species. A set of restraints is also used to define the undissociated strong acid $\mathrm{H}_{3} \mathrm{O}^{+}$which would otherwise not remain centered on the same oxygen as a result of fast proton transfer (Grotthuss mechanism). $n_{d}$ is the number of restrained bonds, $d_{0}$ is the equilibrium value for the bond distance, $k_{d}$ is the coupling constant for the restraint on the bonds. $n_{\alpha}$ is the number of restrained angles, $\alpha_{0}$ is the equilibrium value for the angle, $k_{\alpha}$ the corresponding coupling constant. Distances are in $\AA$, angles in degrees, and coupling constants are in atomic units. 


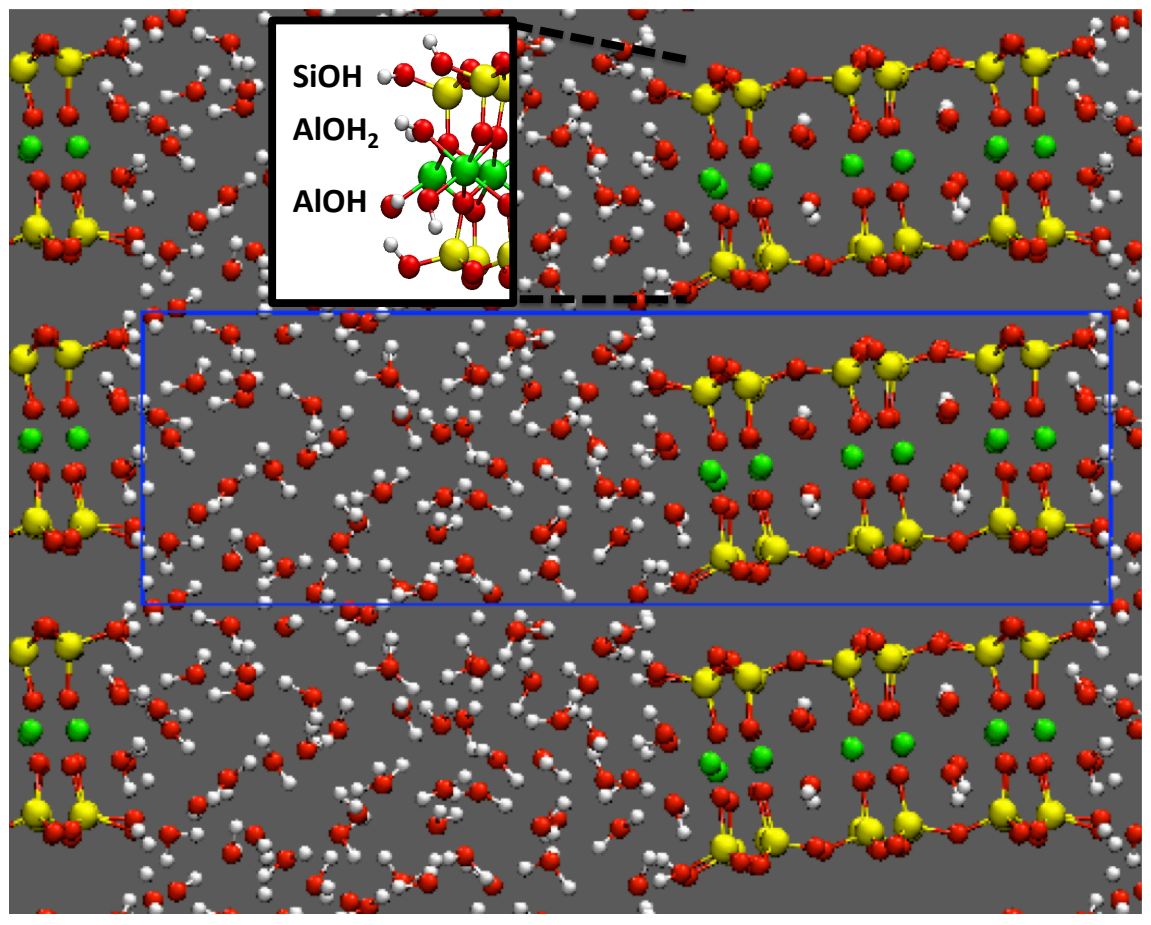

FIG. 1: Simulated system: The (010) pyrophyllite surface faces a slab of liquid water. The insert illustrates the three types of deprotonable sites present on this surface: $\mathrm{SiOH}, \mathrm{AlOH}$ and $\mathrm{AlOH}_{2}$. The latter share the same aluminum atom. Si atoms are represented in yellow, $\mathrm{Al}$ in green, $\mathrm{O}$ in red and $\mathrm{H}$ in white. The simulation box is also indicated, and periodic boundary conditions in all directions are used. 


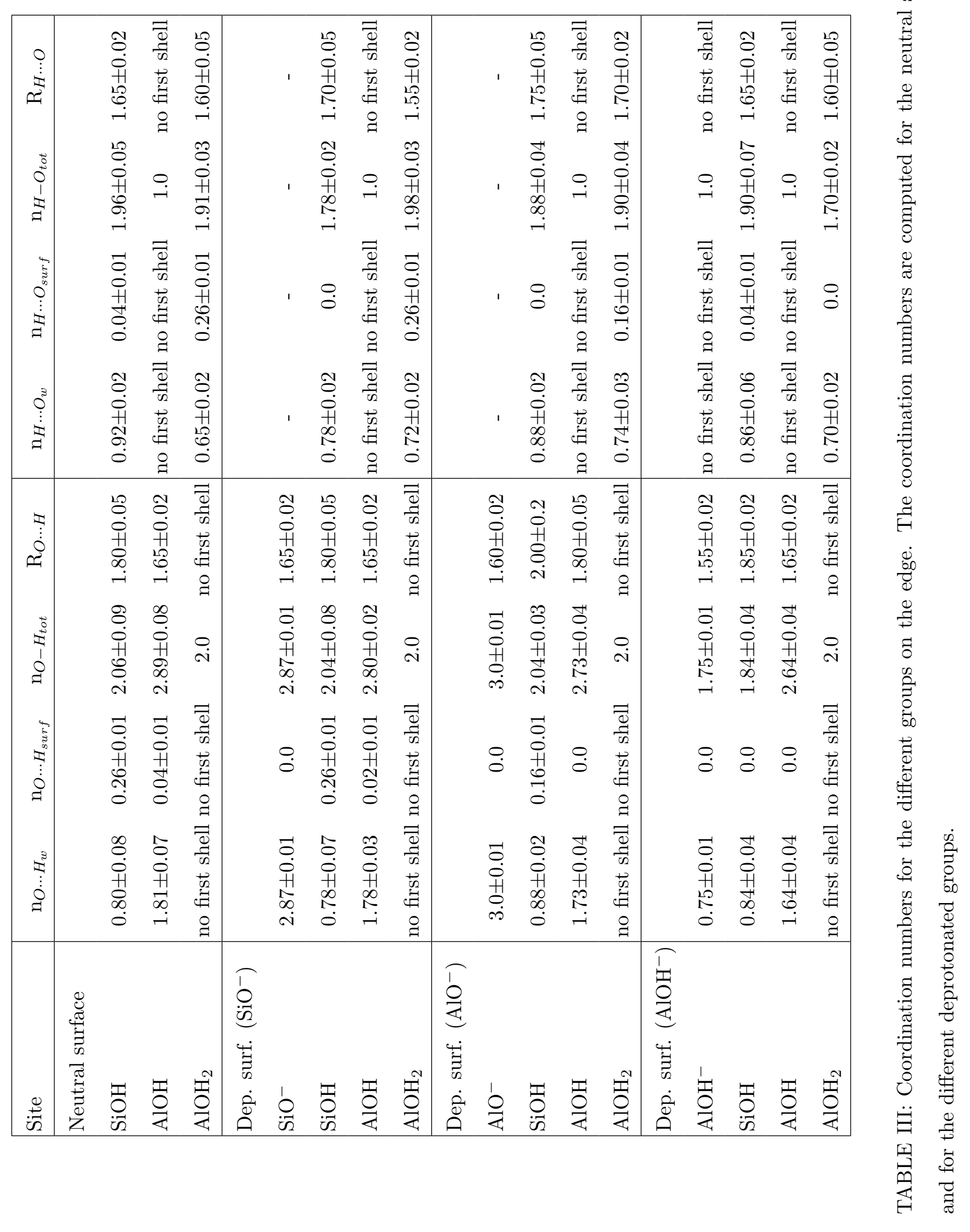




\begin{tabular}{|l|cc|cc|cc|cc|c|}
\hline Site & $\Delta \mathrm{E}_{A H}$ & $\sigma_{A H}$ & $\Delta \mathrm{E}_{A^{-}}$ & $\sigma_{A^{-}}$ & $\Delta \mathrm{E}_{0.5}$ & $\sigma_{0.5}$ & $\Delta \mathrm{A}$ & $\mathrm{p} K_{a}$ & $\lambda$ \\
\hline $\mathrm{SiOH}$ & 7.57 & 1.03 & -6.42 & 1.50 & 0.61 & 0.60 & 0.60 & $6.8 \pm 0.4$ & 6.97 \\
$\mathrm{AlOH}$ & 7.97 & 1.02 & -6.95 & 2.05 & 2.02 & 0.58 & 1.52 & $22.1 \pm 1.0$ & 6.45 \\
$\mathrm{AlOH}_{2}$ & 7.22 & 1.05 & -6.15 & 2.24 & 0.71 & 0.49 & 0.65 & $7.6 \pm 1.3$ & 6.57 \\
\hline
\end{tabular}

TABLE IV: Average vertical deprotonation gap $\Delta \mathrm{E}$ for the protonated $(\mathrm{AH})$, deprotonated $\left(\mathrm{A}^{-}\right)$ and middle point (0.5) states along with the corresponding variance $\sigma$. Energies are in $\mathrm{eV}$. In the case of $\mathrm{SiOH}$ we have considered the $\mathrm{SiOH}$ which is close to the $\mathrm{AlOH}$. However since the solvation structure around the two type of $\mathrm{SiOH}$ is very similar we also expect very close values for their $\mathrm{p} K_{a}$. Also reported are the deprotonation free energy $\Delta A$ calculated with the three point formula, the corresponding $\mathrm{p} K_{a}$ and the reorganization free energy $\lambda=\Delta \mathrm{E}_{A H}-\Delta A$. Statistical errors associated with deprotonation integrals are evaluated as the semi-difference between the value using the first half of the trajectory only or the second half of the trajectory only.

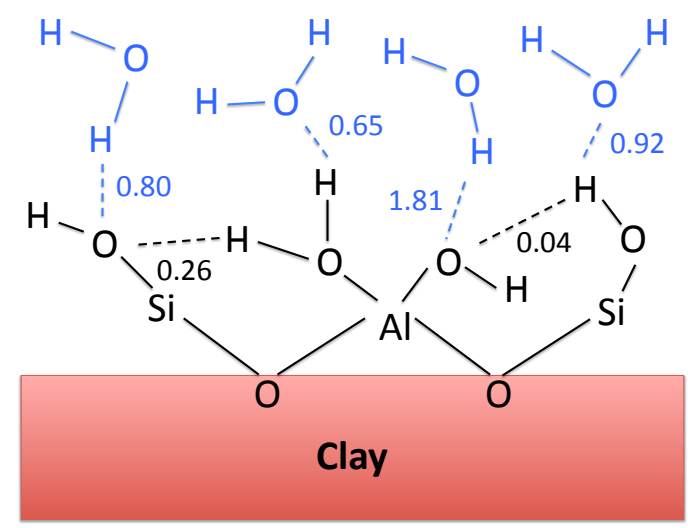

FIG. 2: Schematic view of the hydrogen bond network at the neutral surface. Average numbers of hydrogen bonds for each type of bond are indicated. 


\begin{tabular}{|c|c|c|c|c|}
\hline Atom & Neutral & $\mathrm{SiO}^{-}$ & $\mathrm{AlO}^{-}$ & $\mathrm{AlOH}^{-}$ \\
\hline $\mathrm{Al}(\mathrm{bulk})$ & 2.0 & 2.0 & 2.0 & 2.0 \\
\hline $\mathrm{Al}($ edge $)$ & 1.9 & 1.9 & 1.9 & 1.9 \\
\hline $\mathrm{Al}\left(\mathrm{AlO}^{-}\right)$ & - & - & 1.8 & - \\
\hline $\mathrm{Al}\left(\mathrm{AlOH}^{-}\right)$ & - & - & - & 1.8 \\
\hline Si(bulk) & 1.6 & 1.6 & 1.6 & 1.6 \\
\hline Si(edge) & 1.5 & 1.5 & 1.5 & 1.5 \\
\hline $\mathrm{Si}\left(\mathrm{SiO}^{-}\right)$ & - & 1.5 & - & - \\
\hline $\mathrm{H}(\mathrm{bulk})$ & 0.3 & 0.3 & 0.3 & 0.3 \\
\hline $\mathrm{H}(\mathrm{SiOH})$ & 0.2 & 0.2 & 0.2 & 0.2 \\
\hline $\mathrm{H}(\mathrm{AlOH})$ & 0.2 & 0.1 & 0.1 & 0.1 \\
\hline $\mathrm{H}\left(\mathrm{AlOH}_{2}\right)$ & 0.3 & 0.3 & 0.3 & 0.3 \\
\hline $\mathrm{H}\left(\mathrm{AlOH}^{-}\right)$ & - & - & - & 0.3 \\
\hline $\mathrm{O}(\mathrm{OH})$ & -1.1 & -1.1 & -1.1 & -1.1 \\
\hline $\mathrm{O}($ surface $)$ & -0.8 & -0.8 & -0.8 & -0.8 \\
\hline $\mathrm{O}$ (bridging) & -1.1 & -1.1 & -1.1 & -1.1 \\
\hline $\mathrm{O}(\mathrm{SiOH})$ & -0.5 & -0.5 & -0.5 & -0.5 \\
\hline $\mathrm{O}(\mathrm{AlOH})$ & -0.9 & -0.9 & -0.9 & -0.9 \\
\hline $\mathrm{O}\left(\mathrm{AlOH}_{2}\right)$ & -0.7 & -0.7 & -0.7 & -0.7 \\
\hline $\mathrm{O}\left(\mathrm{SiO}^{-}\right)$ & - & -0.6 & - & - \\
\hline $\mathrm{O}\left(\mathrm{AlO}^{-}\right)$ & - & - & -1.1 & - \\
\hline $\mathrm{O}\left(\mathrm{AlOH}^{-}\right)$ & - & - & - & -0.7 \\
\hline
\end{tabular}

TABLE V: Density-derived atomic partial charges (DDAPC [Blöchl 1995], in elementary charges e), for the neutral surface and the three deprotonated sites. Standard deviations are approximately $0.1 e$. The only noticable change $(|\Delta q| \geq 0.2 e)$ upon deprotonation is observed for the $\mathrm{AlOH}$ site. 


\begin{tabular}{|l|c|}
\hline Bond & Distance $(\AA)$ \\
\hline $\mathrm{Si}-\mathrm{O}(\mathrm{bulk})$ & 1.64 \\
$\mathrm{Si}-\mathrm{O}(\mathrm{SiOH})$ & 1.64 \\
$\mathrm{Si}-\mathrm{O}\left(\mathrm{SiO}^{-}\right)$ & 1.60 \\
\hline $\mathrm{Al}-\mathrm{O}(\mathrm{bulk})$ & 1.94 \\
$\mathrm{Al}-\mathrm{O}(\mathrm{AlOH})$ & 1.86 \\
$\mathrm{Al}-\mathrm{O}\left(\mathrm{AlOH}_{2}\right)$ & 2.05 \\
$\mathrm{Al}-\mathrm{O}\left(\mathrm{AlO}^{-}\right)$ & 1.73 \\
$\mathrm{Al}-\mathrm{O}\left(\mathrm{AlOH}^{-}\right)$ & 1.85 \\
\hline
\end{tabular}

TABLE VI: Metal-oxygen bond length in the bulk clay and on the different edge sites, in the protonated and deprotonated forms. Standard deviations are of the order of $0.03 \AA$.

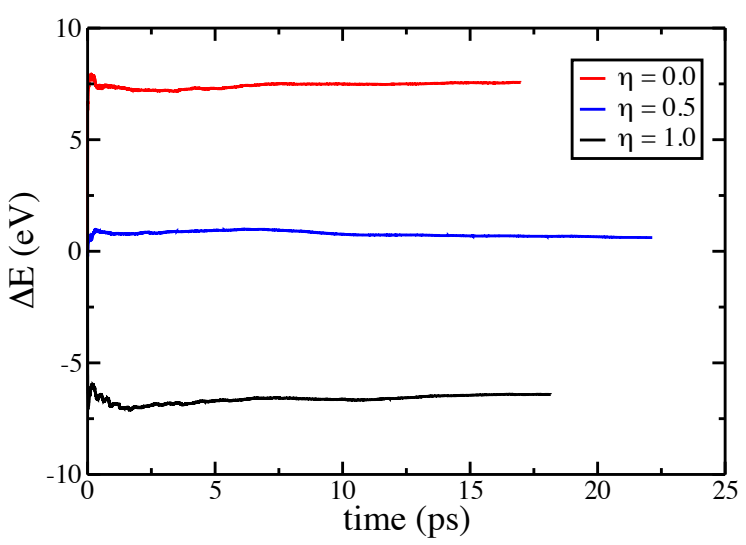

FIG. 3: Evolution of the time-averaged energy gaps for the silanol site, for the three energy surfaces $\eta=0\left(-\mathrm{SiOH}+\mathrm{H}_{2} \mathrm{O}_{a q}\right), 0.5$ (mixed) and $1\left(-\mathrm{SiO}^{-}+\mathrm{H}_{3} \mathrm{O}_{a q}^{+}\right)$. The values reported in Table IV are computed after an equilibration period of 3 ps. 


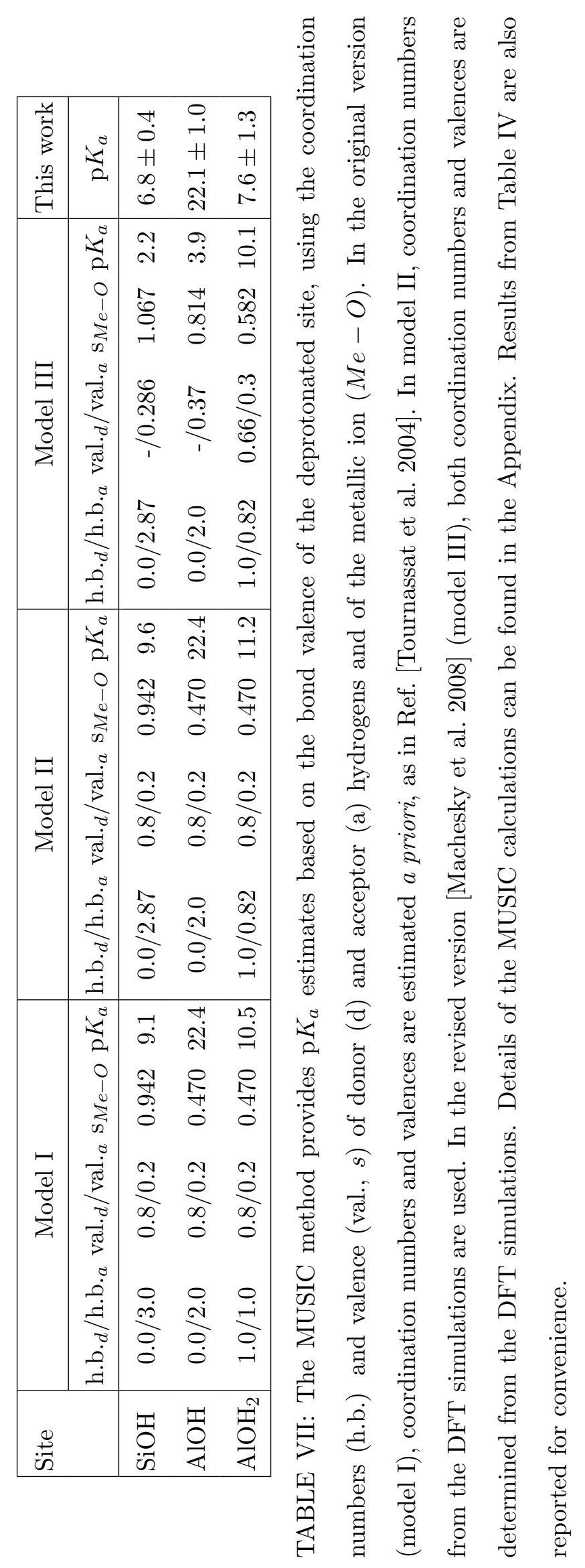


(a)

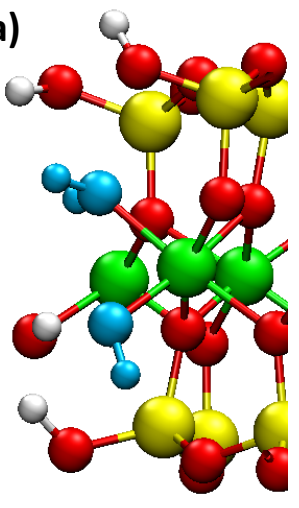

(b)

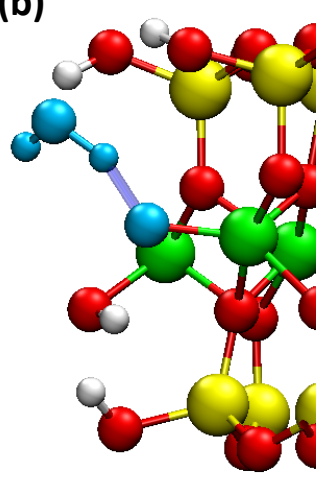

FIG. 4: When the $\mathrm{AlOH}$ site deprotonates, the adjacent $\mathrm{OH}_{2}$ group departs from the aluminum, which remains 5-fold coordinated, and donates a H-bond (blue line) to the $\mathrm{AlO}^{-}$group. Two additional water molecules (not shown) donate H-bonds to this oxygen before and after deprotonation. 